\title{
Prevalence of Episiotomy and Its Associated Factors in University of Gondar Comprehensive Specialized Referral Hospital: A Retrospective Study from Ethiopia
}

\author{
Yonas Teshome ${ }^{1, *}$, Mengistu Mekonen ${ }^{2}$, Tariku Sisay $^{3}$, Getahun Chala $^{4}$, Amanuael Mengistu $^{5}$, \\ Sisay Shewasinad ${ }^{6}$, Negese Worku ${ }^{7}$ \\ ${ }^{1}$ Department of Biomedical Science, College of Medicine, Debre Birhan University, Debre Berhan, Ethiopia \\ ${ }^{2}$ Department of Nursing, College of Medicine and Health Sciences, University of Gondar, Gondar, Ethiopia \\ ${ }^{3}$ Department of Biomedical Science, College of Health Sciences, Mizan Tepi University, Mizan Teferi, Ethiopia \\ ${ }^{4}$ Department of Physiology, College of Health and Medical Sciences, Haramaya University, Haramaya, Ethiopia \\ ${ }^{5}$ Department of Internal Medicine, Debre Berhan Hospital, Debre Berhan, Ethiopia \\ ${ }^{6}$ Department of Nursing, College of Health Sciences, Debre Berhan University, Debre Berhan, Ethiopia \\ ${ }^{7}$ Department of Biomedical Science, College of Medicine, Debre Birhan University, Debre Berhan, Ethiopia
}

\section{Email address:}

teshomeyonas16@yahoo.com (Y. Teshome)

*Corresponding author

\section{To cite this article:}

Yonas Teshome, Mengistu Mekonen, Tariku Sisay, Getahun Chala, Amanuael Mengistu, Sisay Shewasinad, Negese Worku. Prevalence of Episiotomy and Its Associated Factors in University of Gondar Comprehensive Specialized Referral Hospital: A Retrospective Study from Ethiopia. American Journal of Life Sciences. Vol. 8, No. 1, 2020, pp. 9-13. doi: 10.11648/j.ajls.20200801.12

Received: October 23, 2019; Accepted: April 23, 2020; Published: April 29, 2020

\begin{abstract}
Background: Episiotomy is a surgical incision of the perineum during delivery to enlarge the vaginal orifice. It is one of the most commonly performed obstetric intervention world widely. The magnitude of episiotomy varies from population to population. Limited information exists related to the practice of episiotomy in Ethiopia. This study aimed to assess the prevalence of episiotomy and its associated factors in University of Gondar Comprehensive Specialized Referral Hospital, Ethiopia. Methods: Institution based retrospective cross-sectional study was undertaken from March to June 2014 on 306 mothers who had a vaginal delivery in the Hospital. Systematic random sampling technique was employed to select study units. The data were collected using pretested cheek list. Proportion of patients who had episiotomy was calculated and the association between dependent and independent variables was checked using both binary and multiple logistic regression and Chi-square. Results: Prevalence of episiotomy in University of Gondar Comprehensive specialized Referral Hospital was $47.7 \%(n=146)$. Majority $(89.5 \%)$ of the delivery was spontaneous vaginal delivery while vacuum, forceps and destructive delivery were $4.6 \%, 4.6 \%$, and $1.3 \%$ respectively. During pregnancy and delivery, $84 \%$ of mothers had no associated diseases while $8 \%$ had hypertensive disorder, $5 \%$ diabetes mellitus and $3 \%$ of them has other diseases. After multivariate analysis episiotomy was significantly associated with maternal age (15-24 years) ( $p=0.041$, AOR (CI 95\%) $1.65(1.02-2.66))$, primiparity $(p=0.010$, AOR (CI 95\%) $2.61(1.54-4.44))$, prolonged labor $(p=0.001$, COR (CI 95\%) $6.45(2.89-14.38)$ ), and weight of newborn $(p=0.044$, COR (CI 95\%) $2.48(1.16,5.31))$. Conclusion: Prevalence of episiotomies in the institution was $47.7 \%$ and variables that remained associated significantly with episiotomy were maternal age, primiparity, prolonged labor, and newborn weight.
\end{abstract}

Keywords: Episiotomy, Primiparity, Perineum, Prolonged Labour

\section{Introduction}

Episiotomy is a surgical incision of the perineum during delivery to enlarge the vaginal orifice. It is first reported back in 1741 [1] and continues to become part of modern obstetrics [2]. This surgical incision of the perineum is aimed 
to protect the perineum from large tears, speed up birth, reduce postnatal pain, and postnatal urinary incontinence [3]. There is also an evidence that shows association of episiotomy with higher quality of life. According to this study, women who had episiotomy and who experienced perineal symptoms have a better psycho-physical health status [4].

For many years routine episiotomy practice was accepted and taught but now a days restrictive episiotomy performance is promoted than the routine $[1,5]$ for its reduced perineal trauma, reduced suturing, less complications and reduced third and fourth degree perineal lacerations [6]. Even though episiotomy is ascribed to women wellness, since it is a surgical procedure it is not free from risks. Some literatures indicate that episiotomy itself is associated with sexual dysfunction [7], anal sphincter laceration, fecal and urinary incontinence [8], recto-vaginal fistula, perineal pain, dyspareunia, and greater blood loss as compared with vaginal delivery without episiotomy [9, 10]. A study done in Kuopio Finland states that third-degree perineal injuries are more common in both primiparous and multiparous women if episiotomy is performed [11].

Additionally, researchers hadn't found any difference in prevalence of urinary incontinence between women with episiotomy and with spontaneous perineal tears [12-14] as well as in the perinial perception of pain $[15,16]$. Very limited information exists related to the practice of episiotomy in Ethiopia. Therefore, this study aimed to assess the prevalence of episiotomy and its associated factors in University of Gondar Comprehensive Referral Hospital, North West Ethiopia.

\section{Methods}

Retrospective cross sectional study was carried out on selected 306 mothers who gave birth at University of Gondar Comprehensive Specialized Referral Hospital. The Hospital was the only referral and teaching hospital in the area. There were 7,920 births in the study year 2014. Systematic random sampling technique was conducted to select the sample population from medical registration book of the maternity ward. Since there was no research done on the prevalence and associated factors of episiotomy in the hospital, 0.25 proportion was taken from a study in Jimma University to determine the representative sample size.

The sample size was calculated using a single population proportion formula and the medical record books of the selected mothers were extracted for collection of data. Medical record book that contain incomplete data and cesarean delivery were excluded from the study. Data was collected using a pretested check list and revision of medical records was carried out by principal investigator. Independent variables such as socio-demographic factors, weight of the newborn, age of the newborn, health attendant who attended the delivery, parity of the mother, types of delivery, APGAR score, presence of associated disease at birth, absence of previous vaginal birth and prolonged labor were studied along with the dependent variable episiotomy.

The study was conducted in accordance with the guidelines laid down in the Declaration of Helsinki, and the study was approved by the Ethical Committee University of Gondar, College of Health Sciences, Nursing department. Confidentiality, anonymity, neutrality, and accountability was maintain throughout the study.

\section{Statistical Analysis}

Data was entered into Epi Info statistical software then exported to SPSS software version 20 for analysis. Chisquare, binary and multinomial logistic regression were used to compute the association between parameters. P-value of $<0.05$ at $95 \%$ confidence level was considered to be statistically significant in all the analyses.

\section{Result}

The institutional prevalence of episiotomy was $47.7 \%$. Maternal age varied between 15 and 44 years, with an average of 25.9 years for mothers who had episiotomy, and 26.7 year in those without episiotomy. Majority $(89.5 \%)$ of the delivery was spontaneous vaginal delivery while the other types of delivery account only 10.5\% (Figure 1).

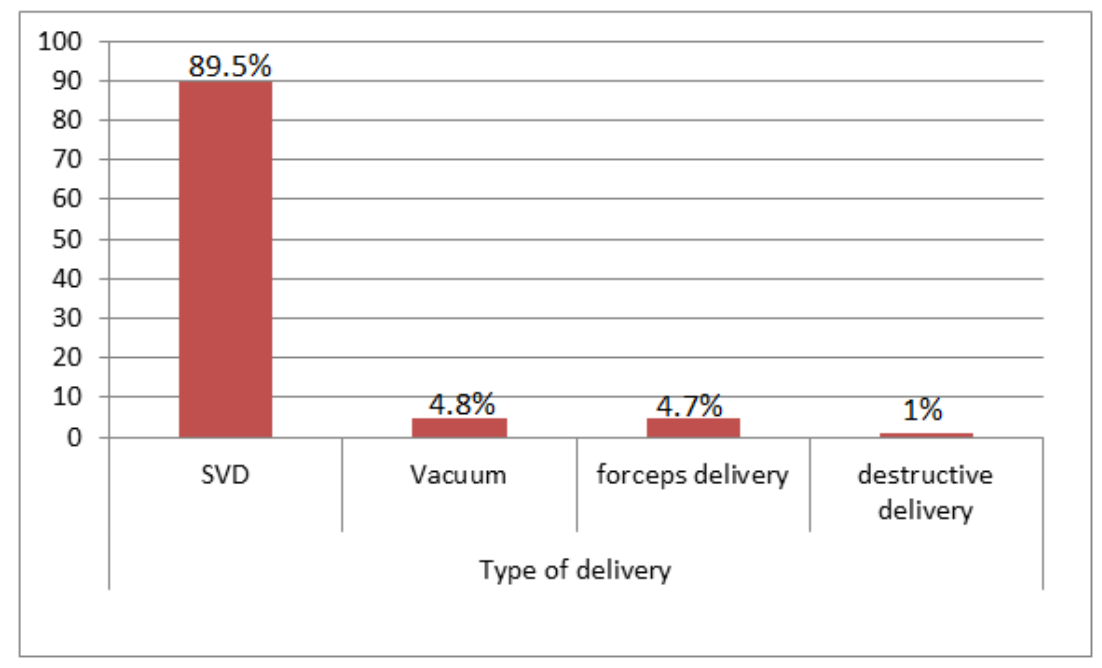

Figure 1. The percentage of type of delivery among mothers giving birth at University of Gondar Comprehensive Specialized Hospital. 
The parity of the mothers was dominantly $215(70.3 \%)$ primipara and most $243(79.4 \%)$ of the children weight were within the range of $2.5 \mathrm{Kg}-3.5 \mathrm{Kg}$. Out of the total 306 study participants 24 (7.8\%) had hypertensive disorder, 17 (5.6\%) diabetes mellitus and $8(2.6 \%)$ of them has other diseases during pregnancy and delivery. (Table 1)

Table 1. Obstetric and obstetric related factors in University of Gondar Comprehensive Specialized Hospital.

\begin{tabular}{|c|c|c|c|}
\hline Factors & & Frequency & Percent (\%) \\
\hline \multirow[t]{3}{*}{ Parity of the mother } & Primipara & 215 & 70.3 \\
\hline & Multipara & 85 & 27.8 \\
\hline & Grandmultipara & 6 & 2 \\
\hline \multirow[t]{3}{*}{ Weight of the Newborn } & $<2.5 \mathrm{Kg}$ & 35 & 11.4 \\
\hline & $2.5 \mathrm{Kg}-3.5 \mathrm{Kg}$ & 243 & 79.4 \\
\hline & $>3.5 \mathrm{Kg}$ & 28 & 9.2 \\
\hline \multirow[t]{2}{*}{ Age of the Newborn } & Preterm & 36 & 11.8 \\
\hline & Post-term & 19 & 6.2 \\
\hline \multirow[t]{4}{*}{ Associated diseases } & Hypertensive & 24 & 7.8 \\
\hline & Diabetes & 17 & 5.6 \\
\hline & Others & 8 & 2.6 \\
\hline & No disease & 257 & 84 \\
\hline \multirow[t]{3}{*}{ Health attendant } & Doctor & 121 & 39.5 \\
\hline & Midwife & 71 & 23.2 \\
\hline & EOS & 89 & 29.1 \\
\hline \multirow[t]{3}{*}{ APGAR score } & $7-10$ & 275 & 89.9 \\
\hline & $4-6$ & 20 & 6.5 \\
\hline & $<4$ & 11 & 3.6 \\
\hline \multirow[t]{2}{*}{ Prolonged labor } & Yes & 45 & 14.7 \\
\hline & No & 261 & 85.3 \\
\hline Absence of previous & Yes & 217 & 70.9 \\
\hline vaginal birth & No & 89 & 29.1 \\
\hline
\end{tabular}

EOS: Emergency Obstetric Surgeon

Factors associated with episiotomy

Multivariate analysis was done for those factors that were significantly associated with binary logistic regression. Accordingly, factors such as maternal age between 15 and 24, primiparity, weight of the newborn and prolonged labor were associated with episiotomy. From the total 146 mothers who had episiotomy, $80.8 \%$ were primipara and this mothers conferred 2.6 fold higher risk of having episiotomy. Similarly, mothers within the age group of 15-24 and with prolonged labor were 1.6, and 6.4 fold at risk of having episiotomy. Newborn weight $>3.5 \mathrm{Kg}$ was a post birth factor that increase the risk of episiotomy by 2.48 fold. No association was observed between Apgar score $(\mathrm{p}=0.486)$, associated disease $(p=0.63)$, health worker $(p=0.14)$, and age of new born $(\mathrm{p}=0.614)$ and episiotomy. (Table 2$)$

Table 2. Factors associated with episiotomy at University of Gondar Comprehensive Specialized Hospital, North West Ethiopia.

\begin{tabular}{|c|c|c|c|c|c|c|c|}
\hline \multirow{3}{*}{ Factors } & & \multicolumn{4}{|c|}{ Episiotomy } & \multirow{3}{*}{ AOR (CI) } & \multirow{3}{*}{$p$} \\
\hline & & \multicolumn{2}{|c|}{ Done (146) } & \multicolumn{2}{|c|}{ Not done (160) } & & \\
\hline & & No & $\%$ & No & $\%$ & & \\
\hline \multirow[t]{3}{*}{ Maternal age } & $15-24$ & 70 & 55.6 & 56 & 44.4 & $1.65(1.02,2.66)$ & 0.041 \\
\hline & $25-34$ & 69 & 43.7 & 89 & 56.3 & $0.82(0.23,1.86)$ & 0.045 \\
\hline & $35-49$ & 7 & 31.8 & 15 & 68.2 & 1 & \\
\hline \multirow[t]{3}{*}{ Parity } & Primipara & 118 & 54.9 & 97 & 45.1 & $2.61(1.54,4.43)$ & 0.010 \\
\hline & Multipara & 28 & 30.8 & 63 & 69.2 & $0.37(0.22,0.61)$ & 0.028 \\
\hline & Grandmultipara & 1 & 26.7 & 5 & 83.3 & 1 & \\
\hline \multirow[t]{3}{*}{ Age of Newborn } & Preterm & 20 & 55.6 & 16 & 44.4 & $1.12(0.72,2.94)$ & 0.83 \\
\hline & Term & 116 & 46.2 & 135 & 53.8 & $0.77(0.37,3.43)$ & 0.61 \\
\hline & Post term & 10 & 52.6 & 9 & 47.4 & 1 & \\
\hline \multirow[t]{3}{*}{ Weight Newborn } & $>3.5 \mathrm{Kg}$ & 23 & 42.9 & 11 & 57.1 & $2.48(1.16,5.31)$ & 0.044 \\
\hline & $2.5-3.5 \mathrm{Kg}$ & 112 & 46.1 & 133 & 53.9 & $0.21(0.08,0.74)$ & 0.038 \\
\hline & $<2.5 \mathrm{Kg}$ & 11 & 62.9 & 16 & 37.1 & 1 & \\
\hline \multirow[t]{3}{*}{ Diseases } & Hypertensive & 19 & 79.2 & 5 & 20.8 & $4.13(2.73,6.81)$ & 0.63 \\
\hline & Diabetes & 21 & 94.1 & 6 & 5.9 & $6.21(1.92,8.35)$ & 0.58 \\
\hline & Non & 106 & 41.2 & 151 & 58.8 & 1 & \\
\hline \multirow[t]{3}{*}{ Health worker } & Doctor & 54 & 44.6 & 67 & 55.4 & 1 & \\
\hline & Midwife & 22 & 31 & 49 & 69 & $0.56(0.47,3.33)$ & 0.20 \\
\hline & EOS & 55 & 61.8 & 34 & 38.2 & $2.01(0.08,5.40)$ & 0.14 \\
\hline APGAR score & $7-10$ & 128 & 46.6 & 147 & 53.4 & 1 & \\
\hline
\end{tabular}




\begin{tabular}{|c|c|c|c|c|c|c|c|}
\hline \multirow{3}{*}{ Factors } & & \multicolumn{4}{|c|}{ Episiotomy } & \multirow{3}{*}{$\operatorname{AOR}(\mathrm{CI})$} & \multirow{3}{*}{$p$} \\
\hline & & \multicolumn{2}{|c|}{ Done (146) } & \multicolumn{2}{|c|}{$\begin{array}{l}\text { Not done (160) } \\
\end{array}$} & & \\
\hline & & No & $\%$ & No & $\%$ & & \\
\hline \multirow{4}{*}{ Prolonged labor } & $4-6$ & 12 & 60 & 8 & 40 & $1.72(0.23,1.96)$ & 0.36 \\
\hline & $<4$ & 6 & 54.5 & 5 & 45.5 & $1.38(0.22,2.43)$ & 0.48 \\
\hline & No & 109 & 41.7 & 152 & 58.2 & 1 & \\
\hline & Yes & 37 & 58 & 8 & 1.4 & $6.45(2.89,14.38)$ & 0.01 \\
\hline
\end{tabular}

AOR: Adjusted Odds Ratio, CI: Confidence Interval, EOS: Emergency Obstetric Surgeon

\section{Discussion}

The prevalence of episiotomy in the Hospital was $47.7 \%$. This result is in line with studies conducted in Western community hospital USA (48\%) [17], and Nigeria (46.6\%) [18] while the finding was higher compared with the studies conducted in Recife, Pernambuko, Brazile (29\%) [19] and Jimma, Ethiopia (25\%) [20]. The difference might be due to different study population characteristics. Additionally, the hospital is the only referral hospital in the area where complicated cases are referred and most primiparas choose to give birth in for the sake of better treatment.

To prevent unnecessary perineal surgical incision, countries are following restricted episiotomy practice and reducing the episiotomy rate. One of such evidence is a study conducted in the United States that shows a decline of episiotomy rate from $60.9 \%$ in 1979 to $24.5 \%$ in 2004 [21]. There is also a study that indicate the possibility of a zero percent episiotomy with a high frequency of intact perineum, reduced need for suturing, and no adverse outcomes such as severe perineal lacerations [22].

After logistic analysis, this study found that mothers within the age group of 15-24 had 1.6 fold higher risk of having episiotomy. This result is similar to the study conducted in Recife, Purnambuko, Brazile which suggests the tenser musculature of adolescents for increased releasing period of cephalic pole presentation which in turn might lead health professionals to do episiotomy [19]. With a similar justification, primiparity and absence of previous vaginal delivery increase the risk of having episiotomy by 2.6 and 2.2 fold in this study which is similar to a study conducted in Australia on Vietnamese born women [23]. As the higher the risk of episiotomy, there is higher third and fourth degree laceration of the perineum [24] that requires suturing. But with the application of a protocol of perineal protection and no episiotomy, there can be reduced need for suture in vaginal deliveries [25].

Additionally, prolonged labor and a newborn weight of $>3.5 \mathrm{~kg}$ were found to increase the rate of performance of episiotomy 6.4 and 2.5 times respectively. Once episiotomy is performed because factors such as primiparity, prolonged labor, birth weight and the like; there can be increased risk of a spontaneous perineal tear or an episiotomy in the second delivery according to a study conducted in Granada, Spain [26]. Therefore, preventive methods such as perineal massage before delivery [27] as well as trainings and awareness creation programs for health professionals might be mandatory to reduce episiotomy rate and to promote evidence based restrictive episiotomy practice [28].

\section{Conclusion}

Prevalence of episiotomy in the institution was $46.7 \%$ and it was associated with age of the mother, primiparity, prolonged labor and birth weight of the new born.

\section{Acknowledgements}

We would like to thank Gondar University, College of health Sciences, Department of Nursing for the unreserved support during the study.

\section{Conflict of Interest}

Authors declare that there are no conflict of interest.

\section{References}

[1] Carroli G and Mignini L. Episiotomy for vaginal birth. Cochrane Database Syst Rev. 2012; (1). doi: 10.1002/14651858.CD000081.pub2.

[2] Klein M. Rites of Passage: Episiotomy and the Second Stage of Labour. Can Fam Physiology. 1988; 34: 2019-2025.

[3] Lappen, J. R., and Gossett, D. R. Changes in episiotomy practice: Evidence-based medicine in action. Expert Review of Obstetrics and Gynecology. 2010; 5 (3): 301-309.

[4] Bertozzi S, Londero A, Fruscalzo A et. al. Impact of episiotomy on pelvic floor disorders and their influence on women's wellness after the sixth month postpartum: a retrospective study. BMC. Women's Health. 2011; 11: 12.

[5] Kumar S, Singh S, Babu K M, Halesha B, and Vikas S. Restricted use of Episiotomy. J Obstet Gynecol India. 2010; 60 (5): $408-412$.

[6] Kutuk M, Dolanbay M, Ozgun M, Ozdemir F, Ozturk A, and Aygen E. Retrospective Analysis of Episiotomy Rate in Erciyes University. Gynecol Obstet Reprod Med. 2014; 20: 10-14.

[7] Sayasneh A and Pandeva I. Postpartum sexual dysfunction: a literature review of risk factors and role of mode of delivery. BJMP. 2010; 3 (2): 316-321.

[8] Signorello, L. B. Midline episiotomy and anal incontinence: retrospective cohort study. $B M J, 2000 ; 320$ (7227): 86-90. doi: 10.1136/bmj.320.7227.86.

[9] Alzahrani H. Does episiotomy prevent perineal trauma? MIDIRS Midwifery Digest. 2014; 24 (4): 478-483. 
[10] Hsieh W, Liang C, Wu D, Chang S, Chueh H, and Chao A. Prevalence and contributing factors of severe perineal damage following episiotomy-assisted vaginal delivery. Taiwanese Journal of Obstetrics \& Gynecology. 2014; 53: 481-485.

[11] Raisanen S, Julkunen K, and Heinonen S. Need for and consequences of episiotomy in vaginal birth: a critical approach. Midwifery. 2010; 26: 348-356.

[12] Langrová P, and Vrublová Y. Relationship between episiotomy and prevalence of urinary incontinence in women 2-5 years after childbirth. Cent Eur J Nurs Midw 2014; 5 (3): 94-98.

[13] Hartmann K, Viswanathan M, Palmieri R, Gartlehner G, Thorp J, and Lohr K. Outcomes of Routine Episiotomy: a systematic review. JAMA. 2005; 293: 2141-2148.

[14] Melo I., Katz L., Coutinho I., and Amorim M. Selective episiotomy vs. implementation of a non-episiotomy protocol: a randomized clinical trial. Reproductive Health. 2014; 11 (1). doi: 10.1186/1742-4755-11-66.

[15] Fodstad K, Staff A and Laine K. Effect of different episiotomy techniques on perineal pain and sexual activity 3 months after delivery. Int Urogynecol J. 2014. doi: 10.1007/s00192-0142401-2.

[16] Fodstad K, Laine K and Staff A. Different episiotomy techniques, postpartum perineal pain, and blood loss: an observational study. Int Urogynecol J. 2014. doi: 10.1007/s00192-012-1960-3.

[17] Allen R and Ronald. Hanson W. Episiotomy in Low-Risk Vaginal Deliveries. J Am Board Fam Pract. 2005; 18: 8-12.

[18] Otoide V, Ogbonmwan S, and Okonofua F. Episiotomy in Nigeria. International Journal of Gynecology \& Obstetrics. 2000; 68: 13-17.

[19] Carvalho C, Souza A, and Filho O. Prevalence and factors associated with practice of episiotomy at a maternity school in Recife, Pernambuko, Brazil. Rev Assoc Med Bras. 2010; 56 (3): 333-339.
[20] Marai W. A two years retrospective review of episiotomy at Jimma Teaching Hospital, southwestern Ethiopia. Ethiop Med J. 2002; 40 (2): 141-148.

[21] Frankman EA, Wang L, Bunker CH, et al. Episiotomy in the United States: has anything changed? Am J Obstet Gynecol. 2009; 200: 573-573.

[22] Amorim M, Franca-Neto A, Leal N, Melo F, Maia S, and Alves J. Is It Possible to Never Perform Episiotomy During Vaginal Delivery. Obstetrics \& Gynecology. 2014; 123: 38.

[23] Trinh, A, Khambalia A, Ampt A, Morris J and Roberts C. Episiotomy rate in Vietnamese-born women in Australia: support for a change in obstetric practice in Viet Nam. Bull World Health Organ. 2013; 91: 350-356. doi: http://dx.doi.org/10.2471/BLT.12.114314.

[24] Leal N, Amorim M, Franca-Neto A, Leite D, Melo F, Alves J. Factors Associated With Perineal Lacerations Requiring Suture in Vaginal Births Without Episiotomy Obstetrics \& Gynecology. 2014; 123: 63-64. doi: 10.1097/01.AOG.0000447369.00977.4c.

[25] Steiner N., Weintraub A. Y., Wiznitzer, A. et al. Episiotomy: the final cut? Arch Gynecol Obstet. 2012; 286: 1369. doi: $10.1007 / \mathrm{s} 00404-012-2460-\mathrm{x}$.

[26] Manzanares S, Cobo D, Martínez M, Mar Sánchez G, and Pineda A. Risk of episiotomy and perineal lacerations recurring after first delivery. Birth. 2013; 40 (4): 307-311. doi: 10.1111/birt.12077.

[27] Dame J, Neher J and Safranek S. Does antepartum perineal massage reduce intrapartum lacerations. Journal of family practice. 2008; 57 (7): 480-481.

[28] Ho J, Pattanittum P, Japaraj R, Turner T, Swadpanich U, and Crowther C. Influence of training in the use and generation of evidence on episiotomy practice and perineal trauma. International Journal of Gynecology and Obstetrics. 2010; 111: 13-18. 